\title{
A Systematic Review Study on Prevalence, Determinants, and Risk Factors of HIV/AIDS among Pacific Countries
}

\section{Masoud Mohammadnezhad1*, Falakika Pasikala Fetuu², Tamara Mangum³ ${ }^{3}$ Julie Qilabasa Alakalia4, Joshua Jeffrey Lucas 5}

${ }^{1}$ Discipline of Health Promotion, Department of Public Health \& Primary Health Care, Fiji National University, Suva, Fiji

${ }^{2}$ Department of Nursing, Ministry of Health, Nuku'alofa, Tonga

${ }^{3}$ Discipline of Emergency Health Management, Department of Public Health \& Primary Health Care, Fiji National University, Suva, Fiji

${ }^{4}$ Department of Public Health, Ministry of Health, Honiara, Solomon Islands

${ }^{5}$ Department of Public Health, Ministry of Health, Weno, Federated States of Micronesia

Email: ${ }^{\star}$ masoud.m@fnu.ac.fj

How to cite this paper: Mohammadnezhad, M., Fetuu, F.P., Mangum, T., Alakalia, J.Q. and Lucas, J.J. (2016) A Systematic Review Study on Prevalence, Determinants, and Risk Factors of HIV/AIDS among Pacific Countries. World Journal of AIDS, 6 , 218-237.

http://dx.doi.org/10.4236/wja.2016.64024

Received: December 9, 2016

Accepted: December 26, 2016

Published: December 29, 2016

Copyright $\odot 2016$ by authors and Scientific Research Publishing Inc. This work is licensed under the Creative Commons Attribution International License (CC BY 4.0).

http://creativecommons.org/licenses/by/4.0/ (c) (i) Open Access

\begin{abstract}
Introduction: The Human Immunodeficiency Virus (HIV) is known as the biggest public health challenge in both developed and developing countries. This systematic review study is carried out to assess the prevalence, determinants, and risk factors of HIV/AIDS in Pacific countries. Methods: This systematic review study applied Cochrane Library Guideline to search, review, apprise, and analyze the articles related to HIV/AIDS. Both qualitative and quantitative articles were published between 2000 to 2016, in English language and were published in databases such as MEDLINE/PubMed, CINAHL, ISI Web of Science, EBSCO, ProQuest, Springer and PyschInfo. A data extraction sheet was made and a descriptive statistic was applied to analyze the data. Results: Fifty-one studies met the study inclusion and exclusion criteria. The United States had the highest frequency of studies on HIV/AIDS (30 studies). The overall prevalence of HIV/AIDS among Pacific islanders was between 1 to 14 percent. The most common determinants of community-based studies were ethnicity and gender, while they were age and ethnicity in the school-based studies and age in the hospital-based studies. The highest risk factors for HIV were substance abuse, number of sexual partners and unprotected sex. Conclusion: The results of the study highlighted the main determinants and risk factors, which provide a framework for public health experts and program planners to focus on different aspects of HIV/AIDS. As HIV/AIDS is a culturally sensitive health issue, developing preventive strategies considering the factors determined in this study will be strongly advised.
\end{abstract}




\section{Keywords}

HIV/AIDS, Prevalence, Determinates, Risk Factors, Pacific

\section{Introduction}

HIV/AIDS is the main cause of the death and disease burden for parts of the world, particularly eastern and southern Africa [1] [2] [3]. Globally, HIV prevalence rate is $0.8 \%$ (46). In 2015, there were about 2.1 million individuals which became newly infected with HIV, bringing the total up to 38.8 million people living with HIV/AIDS [2] [3] [4] the majority of them in low and middle income countries [4] [5]. Young women and adolescent girls between the ages 15 - 24 years old are specifically at high risk of HIV infection compared to men [5] [6]. Eastern and southern Africa regions reported the highest number of HIV cases, about 19 million, followed by western and central Africa with 6.5 million, then Asia and the Pacific region with about 5.1 million in 2015 [2] [4].

In June 2016, 18.2 million people living with HIV received a HIV treatment called antiretroviral therapy (ART), compared to 15.8 million in June 2015 [4] [6]. Despite scientific advances of HIV, most people living with HIV, or at risk for HIV, do not have access to prevention, care and treatment and there is still no cure [5] [7]. The HIV epidemic not only affects the health of individuals, it impacts households, communities and the development and economic growth of nations [6], [8], [9]. Globally, only 3 in 10 adolescent girls and young women aged 15 - 24 years have a comprehensive and accurate knowledge about HIV [6]. Studies have reported that lack of information on prevention and the power to use this information in sexual relationships undermines women's ability to negotiate condom use and engage in safer sex behavior [10] [11].

In the Pacific, Papua New Guinea (PNG) has the highest prevalence with about 34,000 living with HIV in 2009 and the number of newly diagnosed HIV cases in 2010 was 4208 [3] [12]. The rest of the 21 Pacific island countries and territories numbers of newly detected cases increased to 119 in 2012, as compared to 68 in 2010 [13]. Moreover, the HIV/AIDS burden varies by countries. Looking at the gender distribution, in French Polynesia, Guam and New Caledonia most of the reported cases were males, even though more females than males were tested. In contrast to Fiji, it is estimated that half of the HIV diagnosed cases were women [14] [15].

Based on the literature reviews which have been done, there are no systematic reviews on HIV in Pacific islands to comprehend the prevalence, determinants and risk factors of HIV/AIDS. Therefore, this study seeks to understand the prevalence, determinants and risk factors of HIV which exist in the Pacific countries, and help fill the gaps and provide standard information for informed decision making among public health stakeholders that will facilitate reduction of HIV in the future.

\section{Methods}

A systematic review was conducted based on the Cochrane Library Guideline. The 
searches included both qualitative and quantitative studies. Seven online databases were used to find articles including MEDLINE/PubMed, CINAHL, ISI Web of Science, EBSCO, ProQuest, Springer and PyschInfo. They were chosen based on similar studies which have been done in relation to HIIV/AIDS and also accessibility of the databases.

In this study, the inclusion criteria focused on published articles in peer-reviewed journals about Pacific countries between 1st January 2000 and 1st August 2016, written in the English language. Different types of HIV were considered. Studies focused on HIV/AIDS barriers or preventive strategies were excluded. Key words used in the search included: "HIV OR AIDS" AND "factors OR determinant" AND "risk factors" AND "prevalence" AND "incidence" AND "Pacific".

Two independent reviewers reviewed articles in different stages and they discussed with the other authors if there was any disagreement or differences in the assessment process. To find relevant studies three steps were done. The titles of all found studies were scanned and those not relevant or duplicated were omitted at the first stage. The abstract of the remaining articles were reviewed and some articles were omitted at the second stage. Finally, all full text of the remaining articles was reviewed and their quality was assessed. The bibliography of the remaining articles was also searched to find articles not found in the databases.

A data extraction sheet was made and the information of the articles was transferred there. The data extraction sheet had four parts including the characteristics of the article, participants' characteristics, the methodology, and results of the studies. Overall, 45 studies met the study inclusion and exclusion criteria. The search process is shown in Figure 1.

In addition, we found another 6 articles in the bibliography of the remaining articles.

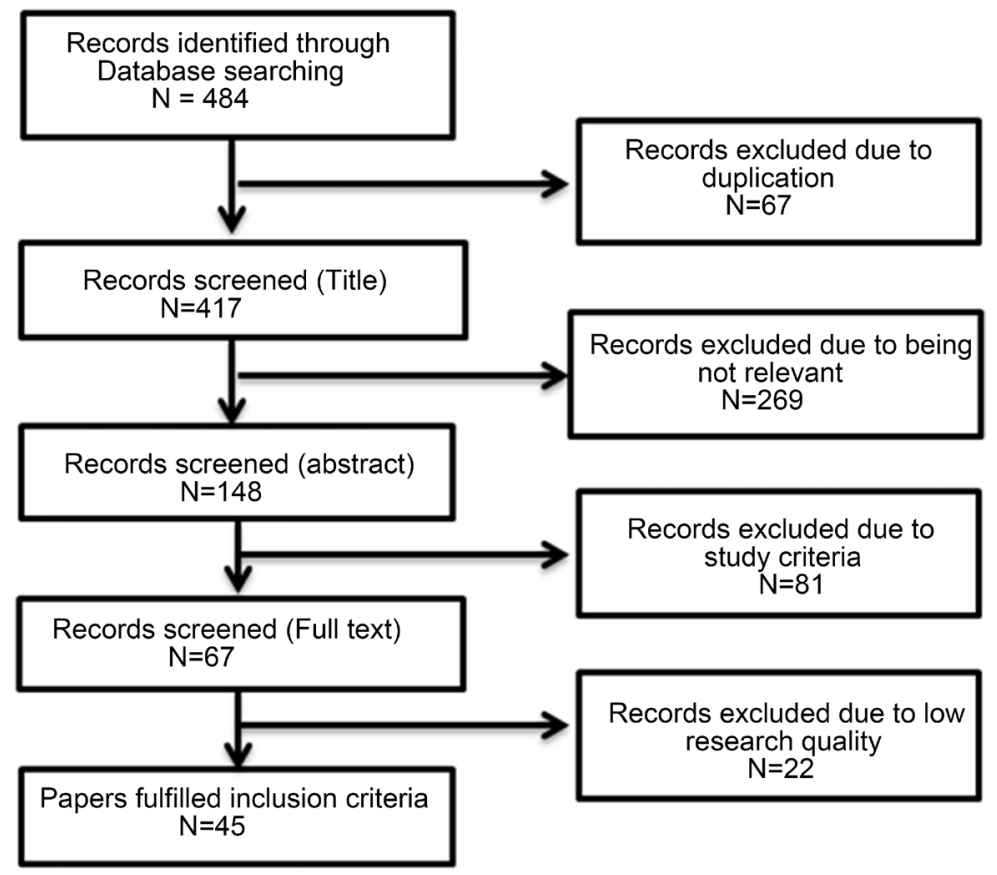

Figure 1. Article selection process. 
Finally, 51 studies were reviewed in this study.

A descriptive analysis was applied and the results were shown as percentages in the form of tables or graphs.

\section{Results}

Table 1 shows the general characteristics of the studies. Many of the studies were conducted after 2010 (52.9\%). More than half of the studies were conducted in American Pacific countries. Many studies focused on both males and females as the target group (45.1\%).

The results the study showed that the United States had the highest number of studies about HIV/AIDS (30 studies), followed by Vanuatu and Papua New Guinea (7 studies each), and the Philippines (4 studies). The results of this study revealed that many studies were conducted with adults aged 20 - 64 years old (31.4\%), while 8 studies (15.7\%) and 5 studies (9.8\%) were conducted among adolescents (below 19) and older people (over 65), respectively.

The results also showed a total of 924,213 people were engaged in the studies including 9924 people (only male), 9380 people (only female), 902,171 people (both male and female), and 2738 people (not reported gender). The study also showed that most studies focused on Gay/Men who have Sex with Men (MSM) (13 studies) as a target group, followed by HIV patients (11 studies), health care workers ( 6 studies), and students (5 studies).

The methodological characteristics of the studies are shown in Table 2. More than half of the studies applied quantitative methodology (56.8\%). Thirty-one studies used questionnaires to collect the data. Purposive sampling (33.4\%) was the most common sampling method.

As Figure 2 shows, most studies were community-based studies (49\%), followed by school-based studies (13.7\%) and hospital/ health care center-based studies (5.9\% each).

Table 1. The general characteristics of studies $(\mathrm{N}=51)$.

\begin{tabular}{ccc}
\hline Variables & Frequency & Percentage \\
\hline Year & 7 & \\
$2000-2004$ & 17 & 13.7 \\
$2005-2009$ & 27 & 33.4 \\
$2010<$ & & 52.9 \\
Region & 14 & \\
South Pacific & 30 & 27.5 \\
American Pacific & 7 & 58.8 \\
Asia-Pacific & & 13.7 \\
Targeted gender & 12 & \\
Male & 5 & 23.5 \\
Female & 23 & 9.8 \\
Female and Male & 11 & 45.1 \\
Not reported & & 21.6 \\
\hline
\end{tabular}


Table 2. Methodological characteristics of studies $(\mathrm{N}=51)$.

\begin{tabular}{ccc}
\hline Variables & Frequency & Percentage \\
\hline Type of studies & 29 & 56.8 \\
Quantitative studies & 20 & 39.2 \\
Qualitative studies & 1 & 2.0 \\
Mixed method study & 1 & 2.0 \\
Interventional study & & \\
Data collection tools & 31 & 60.8 \\
Questionnaire & 4 & 7.8 \\
In-depth Interview & 10 & 19.6 \\
Focus group discussion & 6 & 11.7 \\
Questionnaires \& Lab test & & \\
Sampling method & 12 & 23.5 \\
Convenience & 9 & 17.6 \\
Snowball & 17 & 33.4 \\
Purposive & 12 & 23.5 \\
Random & 1 & 2 \\
Stratified & & \\
\hline
\end{tabular}

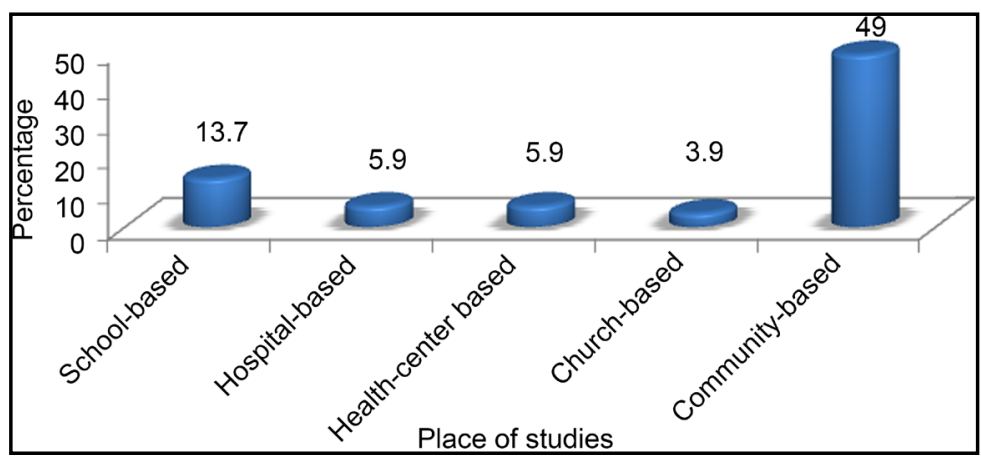

Figure 2. Frequency of studies based on the place where conducted.

\subsection{Prevalence of HIV}

Out of 51 reviewed articles, 30 were quantitative studies and only four of them mentioned the prevalence of HIV. The overall prevalence among Pacific island people is between $1 \%-14 \%$, with the majority being amongst male adolescents and adults. The highest prevalence (14\%) is among MSM Asia Pacific Islanders; $12.8 \%$ is the second highest amongst MSM, substance abusers and incarcerated persons Asia Pacific Islanders. The lowest prevalence (1\%) is among persons diagnosed with HIV infection Asia Pacific Islander.

\subsection{Determinants of HIV}

Out of 51 reviewed articles, 30 were quantitative studies and 28 mentioned the determinants regarding HIV. Determinants of HIV were categorized into 3 main places: community, school and hospital. The most common determinants of community-based studies are ethnicity and gender ( 7 studies, $25 \%$ respectively), followed by age ( 6 studies, $21.4 \%)$ and social support network and sex (5 studies, $17.8 \%$, respectively). The least common determinants are work environment, knowledge level and individual 
lifestyle ( 1 study, $3.4 \%$, respectively). In the school place, the most common determinants are age, ethnicity and individual lifestyle (2 studies, $7.1 \%$, respectively) with the least common ones being social support network and gender (1 study, 3.4\%, respectively). With the hospital place, the biggest determinant is age (2 studies, 7.1\%) and the least ones are ethnicity, education and income (1 study, 3.4\%, respectively).

Out of 51 reviewed articles, 20 were qualitative studies, all of them mentioning the determinants of HIV based on the participants' perspective. Most study participants believed gender to be the main determinant ( 8 studies, $40 \%$ ), followed by ethnicity ( 6 studies, 30\%) and culture (4 studies, 20\%). The least common ones are sex, beliefs, work environment, social cultural factors, individual lifestyle and education (1 study, 5\%, respectively).

\subsection{Risk factors for HIV}

Out of 51 reviewed articles, 30 were quantitative studies and 17 reported the risk factors for HIV. The highest risk factors for HIV were substance abuse, number of sexual partners and unprotected sex ( 5 studies, $29.4 \%$, respectively), followed by heterosexual contact (4 studies, 23.5\%), along with low level condom use and having had sex before age 15 ( 3 studies, $17.6 \%$, respectively).

Out of 51 reviewed articles, 20 were qualitative studies and only 2 mentioned the risk factors for HIV. These are community-based and church-based articles. With the community-based study, psychological and behavioral risks were identified as the highest risk factors and then number of sexual partners, with unprotected sex being the risk identified as the highest in the church-based study.

\subsection{Interventional Study}

As the results revealed, one interventional study, which was a community-based participatory research, was implemented to prevent adolescent pregnancy and issues related to STIs and HIV among Filipino Americans. The results showed that culturally tailored interventions increased the participants' awareness, facilitated the ability to talk openly about sex, STDs and HIV, and empowered families to solve their problems by themselves in their community $(\mathrm{p}<0.001)$.

\section{Discussion}

HIV prevalence levels can vary considerably between different countries and between different populations within a country. In this study, the results showed the prevalence of HIV among Pacific islanders diagnosed with HIV ranges from $1 \%$ to $14 \%$. This prevalence is very low as compared with what is observed among MSM [16] but is considered high as it is indicates suboptimum access to health care [17]. However, this is consistent with a study done in Iran (7.14 to 15.95\%) in 2010 and South Africa (12.2\%) in 2012 [11] [18]. In addition, this study found HIV prevalence was more common among male Pacific islanders than female. This suggests that Pacific island males are more likely to engage more frequently in high risk behaviors [14] [15]. Another study 
supported that men are unaware of serostatus, cultural norms and structural factors including poverty and discrimination [19] [20].

HIV/AIDS is a virus that is transmitted in bodily fluids, a blood-borne disease. The mode of transmission for HIV/AIDS is via unprotected sexual intercourse, sharing needles, and from a mother who is HIV positive to her unborn child. The most common modes of HIV transmission identified in the Pacific Islands Countries and Territories (PICTs), excluding Papua New Guinea, are unprotected heterosexual sexual contact and male to MSM contact [21]. This study stated the most common risk factors for HIV/AIDS in the Pacific region were associated with substance abuse, number of sexual partners, and unprotected sex, followed by unprotected heterosexual sexual contact, as stated in 4 studies, and low level condom use and having sexual intercourse before the age of 15 years, as stated in 3 studies. These results show there is a higher chance for Pacific islanders to acquire HIV/AIDS because of substance abuse, having multiple sexual partners and unprotected sex. Substance abuse is defined as excessive substance use, such as drugs and alcohol. Excessive drug and alcohol use can increase the chances of having unprotected sexual intercourse and having multiple sexual partners. As stated in drug and alcohol consumption and sexual risk behavior among young adults, "people who are intoxicated and cannabis users were associated with having more than one sexual partner and unprotected sexual contact.

Based on the 30 quantitative studies conducted in the Asia Pacific region, 13 stated that sex and gender are common determinants for HIV. Both genders can acquire HIV/AIDS if they do not practice safe sex, and gender roles are in every area, which increases or reduces chances of HIV infection [11]. The findings show that HIV is more prevalent among men than women. According to the report of the United Nations program on HIV/AIDS (UNAIDS) about the Asia Pacific region, it states that men who have sex with men are the ones with the greater risk for acquiring HIV/AIDS [22]. Also, Van Griensven, F., et al. (2010) support that men are sexually active with the combination of strong sexual desire, sexual opportunities and HIV risk factors and behaviors likely fuel their chance of getting infected [23]. Another study conducted in the Pacific state that French Polynesia, Guam, and New Caledonia's highest mode of HIV transmission is through heterosexual contact and MSM [24]. On the other hand, globally, women are more vulnerable to the infection because of their reproduction role and their low socioeconomic position in society [25].

This study's results showed that most of the participants are adults. It is consistent with the CDC report for the United States; they found the highest age group diagnosed with HIV (37\%) were aged 20 - 29, 24\% were aged 30 - 39, 17\% were aged 40 - 49 [26]. This may occur due to adults are more likely to be unaware of their infection status which increases the chances of infecting others through unprotected sex [6].

A social support network has been mentioned in many situations in this study; it has a negative impact on HIV, which is consistent with our results because of the discrimination and stigmatization against people living with HIV [25]. Many studies mention various causes contributing to social stigma [27]. HIV is associated with already stig- 
matized groups, such as sex workers and gay or lesbian persons. HIV is often viewed as divine punishment for misbehavior. Therefore, other studies supported that many people are afraid of infection due to ignorance about the mechanisms of HIV transmission in Nigeria and many other countries [27]. Ethnicity is another determinant for HIV/AIDS in the Pacific, which is associated with population distribution, socioeconomic status, and mechanism of HIV transmission [28].

Furthermore, individual lifestyle is another determinant for HIV/AIDS in the Pacific. Sexual behavior associated with HIV infection among Pacific islanders is due to poverty [29]. In contrast, another study conducted by Collection on Adverse Events of Anti-HIV drugs study group found that there is no association between lifestyle factors, including lifetime use of alcohol, smoking, marijuana and HIV disease [30]. Similarly, another study involving only HIV-positive women, found that lifestyle factors did not affect risk of HIV progression [31].

Overall, our results showed that MSM and unprotected heterosexual contact among Pacific islanders are the main causes of acquiring HIV/AIDS in the Pacific region. The studies showed that HIV prevalence is higher in Pacific men than women due to the risk factors such as substance abuse, having multiple sexual partners, unprotected sexual behavior, and inconsistent condom use. To prevent HIV/AIDS in the Pacific, policy makers and health professionals are encouraged to provide culturally acceptable and appropriate preventive practices and better services that will decrease the HIV prevalence and mode of HIV transmission in the Pacific region.

This study had some limitations. Only English-language articles were searched so that the presence of publication bias in this review study is a possibility. Certain key words may have been missed in the search literature; however, the comprehensive search term list was used to minimize this limitation.

\section{References}

[1] Murray, C.J., et al. (2014) Global, Regional, and National Incidence and Mortality for HIV, Tuberculosis, and Malaria during 1990-2013: A Systematic Analysis for the Global Burden of Disease Study 2013. The Lancet, 384, 1005-1070. https://doi.org/10.1016/S0140-6736(14)60844-8

[2] Steel, N. (2016) Estimates of Global, Regional, and National Incidence, Prevalence, and Mortality of HIV, 1980-2015: The Global Burden of Disease Study 2015. Lancet HIV, 3, e361-e387. https://doi.org/10.1016/S2352-3018(16)30087-X

[3] UNAIDS (1996) Global AIDS Response Progress Reporting 2015. UNAIDS and World Health Organization, Geneva. http://www.unaids.org/sites/default/files/media_asset/JC2702_GARPR2015guidelines_en.p df

[4] World Health Organization (2013) Global Tuberculosis Report 2013.

[5] UNAIDS (2010) Global Report: UNAIDS Report on the Global AIDS Epidemic 2010.

[6] Centers for Disease Control and Prevention, HIV/AIDS Basic Statistics. http://www.cdc.gov/hiv/basics/statistics.html

[7] Moyer, V.A. (2013) Screening for HIV: US Preventive Services Task Force Recommendation Statement. Annals of Internal Medicine, 159, 51-60. 
https://doi.org/10.7326/0003-4819-159-1-201307020-00645

[8] UNAIDS (2010) AIDS Scorecards: Overview: UNAIDS Report on the Global AIDS Epidemic 2010.

[9] Moore, R.D. (2011) Epidemiology of HIV Infection in the United States: Implications for Linkage to Care. Clinical Infectious Diseases, 52, S208-S213. https://doi.org/10.1093/cid/ciq044

[10] Millett, G.A., et al. (2012) Comparisons of Disparities and Risks of HIV Infection in Black and Other Men Who Have Sex with Men in Canada, UK, and USA: A Meta-Analysis. The Lancet, 380, 341-348. https://doi.org/10.1016/S0140-6736(12)60899-X

[11] Haghdoost, A.A., et al. (2011) Modelling of HIV/AIDS in Iran Up to 2014. Journal of AIDS and HIV Research, 3, 231-239. https://doi.org/10.5897/JAHR11.030

[12] WHO (2013) Global Update on HIV Treatment 2013: Results, Impact and Opportunities.

[13] Coghlan, B., et al. (2011) The HIV Epidemic in Papua New Guinea. JAIDS Journal of Acquired Immune Deficiency Syndromes, 58, e48-e51. https://doi.org/10.1097/qai.0b013e3182293417

[14] Mathers, B.M., et al. (2010) HIV Prevention, Treatment, and Care Services for People Who Inject Drugs: A Systematic Review of Global, Regional, and National Coverage. The Lancet, 375, 1014-1028. https://doi.org/10.1016/S0140-6736(10)60232-2

[15] WHO (2010) World Health Statistics 2010.

[16] Heiligenberg, M., et al. (2012) High Prevalence of Sexually Transmitted Infections in HIV-Infected Men during Routine Outpatient Visits in the Netherlands. Sexually Transmitted Diseases, 39, 8-15. https://doi.org/10.1097/OLQ.0b013e3182354e81

[17] Millett, G.A., et al. (2010) A Way Forward: The National HIV/AIDS Strategy and Reducing HIV Incidence in the United States. Journal of Acquired Immune Deficiency Syndromes, 55, S144-S147. https://doi.org/10.1097/qai.0b013e3181fbcb04

[18] Setswe, G. and Zuma, K. (2012) HIV, AIDS and Tuberculosis Epidemics in South Africa: Overview and Responses. In: Nyamnjoh, F., Pillay, U., Hagg, G. and Jansen, J., Eds., State of the Nation: South Africa: 2012-2013, HSRC Press, Cape Town, 485-516.

[19] Beyrer, C., et al. (2012) Global Epidemiology of HIV Infection in Men Who Have Sex with Men. The Lancet, 380, 367-377. https://doi.org/10.1016/S0140-6736(12)60821-6

[20] Finlayson, T.J., et al. (2011) HIV Risk, Prevention, and Testing Behaviors among Men Who Have Sex with Men-National HIV Behavioral Surveillance System, 21 US Cities, United States, 2008. MMWR Surveillance Summaries, 60, 1-34.

[21] Wanyeki, L.M. (2012) The International Criminal Court's Cases in Kenya: Origin and Impact. Institute for Security Studies Papers, No. 237, 28 p.

[22] UNAIDS (2016) Global AIDS Update 2016. Joint United Nations Programme on HIV/ AIDS, 2016

http://www.unaids.org/sites/default/files/media_asset/global-AIDS-update-2016_en.pdf

[23] Van Griensven, F., et al. (2010) Trends in HIV Prevalence, Estimated HIV Incidence, and Risk Behavior among Men Who Have Sex with Men in Bangkok, Thailand, 2003-2007. Journal of Acquired Immune Deficiency Syndromes, 53, 234-239. https://doi.org/10.1097/QAI.0b013e3181c2fc86

[24] UNAIDS (2011) Global Plan towards the Elimination of New HIV Infections among Children By 2015.

[25] Awoleye, O.J. and Thron, C. (2015) Determinants of Human Immunodeficiency Virus (HIV) Infection in Nigeria: A Synthesis of the Literature. Journal of AIDS and HIV Re- 
search, 7, 117-129. https://doi.org/10.5897/JAHR2015.0338

[26] Centers for Disease Control and Prevention (2014) HIV in the United States: At a Glance. 2013.

[27] Odimegwu, C., Adedini, S.A. and Ononokpono, D.N. (2013) HIV/AIDS Stigma and Utilization of Voluntary Counseling and Testing in Nigeria. BMC Public Health, 13, 465. https://doi.org/10.1186/1471-2458-13-465

[28] Stutterheim, S.E., Bos, A.E.R., Pryor, J.B., Brands, R., Liebregts, M. and Schaalma, H.P. (2011) Psychological and Social Correlates of HIV Status Disclosure: The Significance of Stigma Visibility. AIDS Education and Prevention, 23, 382. https://doi.org/10.1521/aeap.2011.23.4.382

[29] Viner, R.M., et al. (2012) Adolescence and the Social Determinants of Health. The Lancet, 379, 1641-1652. https://doi.org/10.1016/S0140-6736(12)60149-4

[30] Data Collection on Adverse Events of Anti-HIV drugs (D:A:D) Study Group, et al. (2010) Factors Associated with Specific Causes of Death amongst HIV-Positive Individuals in the D: A: D Study. AIDS, 24, 1537-1548.

[31] Nakagawa, F., et al. (2012) Projected Life Expectancy of People with HIV According to Timing of Diagnosis. AIDS, 26, 335-343. https://doi.org/10.1097/QAD.0b013e32834dcec9

[32] Chen, W.-T., et al. (2014) Acculturation and Perceived Stress in HIV+ Immigrants: Depression Symptomatology in Asian and Pacific Islanders. AIDS Care, 26, 1581-1585.

https://doi.org/10.1080/09540121.2014.936816

[33] Wortley, P.M., Metler, R.P., Hu, D.J. and Fleming, P.L. (2000) AIDS among Asians and Pacific Islanders in the United States. American Journal of Preventive Medicine, 18, 208-214. https://doi.org/10.1016/S0749-3797(99)00159-2

[34] Kang, E., Rapkin, B.D. and DeAlmeida, C. (2006) Are Psychological Consequences of Stigma Enduring or Transitory? A Longitudinal Study of HIV Stigma and Distress among Asians and Pacific Islanders Living with HIV Illness. AIDS Patient Care \& STDs, 20, 712-723. https://doi.org/10.1089/apc.2006.20.712

[35] Lee, S.J. and Rotheram-Borus, M.J. (2009) Beyond the "Model Minority" Stereotype: Trends in Health Risk Behaviors among Asian/Pacific Islander High School Students. Journal of School Health, 79, 347-354. https://doi.org/10.1111/j.1746-1561.2009.00420.x

[36] Van Gemert, C., et al. (2014) Chlamydia Prevalence and Associated Behaviours among Female Sex Workers in Vanuatu: Results from an Integrated Bio-Behavioural Survey, 2011. AIDS and Behavior, 18, 2040-2049. https://doi.org/10.1007/s10461-014-0791-2

[37] Adih, W.K., Campsmith, M., Williams, C.L., Hardnett, F.P. and Hughes, D. (2011) Epidemiology of HIV among Asians and Pacific Islanders in the United States, 2001-2008. Journal of the International Association of Physicians in AIDS Care (JIAPAC), 10, 150-159. https://doi.org/10.1177/1545109711399805

[38] Zaidi, I.F., et al. (2005) Epidemiology of HIV/AIDS among Asians and Pacific Islanders in the United States. AIDS Education and Prevention, 17, 405. https://doi.org/10.1521/aeap.2005.17.5.405

[39] Sasaki, P.Y. and Kameoka, V.A. (2009) Ethnic Variations in Prevalence of High-Risk Sexual Behaviors among Asian and Pacific Islander Adolescents in Hawaii. American Journal of Public Health, 99, 1886-1892. https://doi.org/10.2105/AJPH.2008.133785

[40] Choi, K.-H., Paul, J., Ayala, G., Boylan, R. and Gregorich, S.E. (2013) Experiences of Discrimination and Their Impact on the Mental Health among African American, Asian and Pacific Islander, and Latino Men Who Have Sex with Men. American Journal of Public Health, 103, 868-874. https://doi.org/10.2105/AJPH.2012.301052 
[41] Salud, M.C., Marshak, H.H., Natto, Z.S. and Montgomery, S. (2014) Exploring HIV-Testing Intentions in Young Asian/Pacific Islander (API) Women as It Relates to Acculturation, Theory of Gender and Power (TGP), and the AIDS Risk Reduction Model (ARRM). AIDS Care, 26, 642-647. https://doi.org/10.1080/09540121.2013.841836

[42] Lachowsky, N.J., Saxton, P.J.W., Dickson, N.P., Hughes, A.J., Summerlee, A.J.S. and Dewey, C.E. (2014) Factors Associated with Recent HIV Testing among Younger Gay and Bisexual Men in New Zealand, 2006-2011. BMC Public Health, 14, 294.

https://doi.org/10.1186/1471-2458-14-294

[43] Cruz, A.R., Castrillón, M.A., Minotta, A.Y., Rubiano, L.C., Castaño, M.C. and Salazar, J.C. (2013) Gestational and Congenital Syphilis Epidemic in the Colombian Pacific Coast. SeXually Transmitted Diseases, 40, 813-818. https://doi.org/10.1097/OLQ.0000000000000020

[44] Han, N., et al. (2015) HIV and Aging: Insights from the Asia Pacific HIV Observational Database (APHOD). HIV Medicine, 16, 152-160. https://doi.org/10.1111/hiv.12188

[45] Takahashi, L.M., Magalong, M.G., DeBell, P. and Fasudhani, A. (2006) HIV and AIDS in Suburban Asian and Pacific Islander Communities: Factors Influencing Self-Efficacy in HIV Risk Reduction. AIDS Education \& Prevention, 18, 529-545. https://doi.org/10.1521/aeap.2006.18.6.529

[46] Kahle, E.M., Freedman, M.S. and Buskin, S.E. (2005) HIV Risks and Testing Behavior among Asians and Pacific Islanders: Results of the HIV Testing Survey, 2002-2003. Journal of the National Medical Association, 97, $13 \mathrm{~S}$.

[47] Hahm, H.C., Song, I.H., Ozonoff, A. and Sassani, J.C. (2009) HIV Testing among Sexually Experienced Asian and Pacific Islander Young Women: Association with Routine Gynecologic Care. Women's Health Issues, 19, 279-288. https://doi.org/10.1016/j.whi.2009.05.001

[48] Wong, F.Y., Campsmith, M.L., Nakamura, G.V., Crepaz, N. and Begley, E. (2004) HIV Testing and Awareness of Care-Related Services among a Group of HIV-Positive Asian Americans and Pacific Islanders in the United States: Findings from a Supplemental HIV/AIDS Surveillance Project. AIDS Education and Prevention, 16, 440. https://doi.org/10.1521/aeap.16.5.440.48736

[49] Wong, F.Y., et al. (2012) HIV Testing and Management: Findings from a National Sample of Asian/Pacific Islander Men Who Have Sex with Men. Public Health Reports, 127, 186194.

[50] Do, T.D., Hudes, E.S., Proctor, K. Han, C.-S. and Choi, K.-H. (2006) HIV Testing Trends and Correlates among Young Asian and Pacific Islander Men Who Have Sex with Men in Two US Cities. AIDS Education and Prevention, 18, 44. https://doi.org/10.1521/aeap.2006.18.1.44

[51] Muller, S. and Sami, V.N. (2012) HIV-TB the Deadly Duo, the Biggest Health Challenge in Fiji. BMC Infectious Diseases, 12, O22. https://doi.org/10.1186/1471-2334-12-S1-O22

[52] Hahm, H., Lee, J., Zerden, L., Ozonoff, A., Amodeo, M. and Adkins, C. (2008) Longitudinal Effects of Perceived Maternal Approval on Sexual Behaviors of Asian and Pacific Islander (API) Young Adults. Journal of Youth and Adolescence, 37, 74-84. https://doi.org/10.1007/s10964-007-9234-y

[53] Kang, E., Rapkin, B.D., Remien, R.H., Mellins, C.A. and Oh, A. (2005) Multiple Dimensions of HIV Stigma and Psychological Distress among Asians and Pacific Islanders Living with HIV Illness. AIDS and Behavior, 9, 145-154. https://doi.org/10.1007/s10461-005-3896-9

[54] Hahm, H.C., Lee, J., Ozonoff, A. and Amodeo, M. (2007) Predictors of STDs among Asian and Pacific Islander Young Adults. Perspectives on Sexual and Reproductive Health, 39, 231-239. https://doi.org/10.1363/3923107 
[55] Lowry, R., Eaton, D.K., Brener, N.D. and Kann, L. (2011) Prevalence of Health-Risk Behaviors among Asian American and Pacific Islander High School Students in the US, 2001-2007. Public Health Reports, 126, 39-49.

[56] Foliaki, S., et al. (2014) Prevalence of HPV Infection and Other Risk Factors in a Fijian Population. Infectious Agents and Cancer, 9, 14. https://doi.org/10.1186/1750-9378-9-14

[57] Huang, Z.J., Wong, F.Y., de Leon, J.M. and Park, R.J. (2008) Self-Reported HIV Testing Behaviors among a Sample of Southeast Asians in an Urban Setting in the United States. AIDS Education and Prevention, 20, 65. https://doi.org/10.1521/aeap.2008.20.1.65

[58] Saewyc, E., Skay, C., Richens, K., Reis, E., Poon, C. and Murphy, A. (2006) Sexual Orientation, Sexual Abuse, and HIV-Risk Behaviors among Adolescents in the Pacific Northwest. American Journal of Public Health, 96, 1104-1110. https://doi.org/10.2105/AJPH.2005.065870

[59] Choi, K.H., Ayala, G., Paul, J., Boylan, R. and Gregorich, S.E. (2013) Social Network Characteristics and HIV Risk among African American, Asian/Pacific Islander, and Latino Men Who Have Sex with Men. Journal of Acquired Immune Deficiency Syndromes, 64, 496-501. https://doi.org/10.1097/qai.0b013e3182a7ee52

[60] Han, C.-S., Ayala, G., Paul, J.P., Boylan, R., Gregorich, S.E. and Choi, K.-H. (2015) Stress and Coping with Racism and Their Role in Sexual Risk for HIV among African American, Asian/Pacific Islander, and Latino Men Who Have Sex with Men. Archives of Sexual Behavior, 44, 411-420. https://doi.org/10.1007/s10508-014-0331-1

[61] Nemoto, T., Iwamoto, M., Kamitani, E., Morris, A. and Sakata, M. (2011) Targeted Expansion Project for Outreach and Treatment for Substance Abuse and HIV Risk Behaviors in Asian and Pacific Islander Communities. AIDS Education and Prevention, 23, 175.

https://doi.org/10.1521/aeap.2011.23.2.175

[62] Zayeri, F., Ghane, E.T. and Borumandnia, N. (2016) Assessing the Trend of HIV/AIDS Mortality Rate in Asia and North Africa: An Application of Latent Growth Models. Epidemiology and Infection, 144, 548-555. https://doi.org/10.1017/S0950268815001351

[63] Kennedy, E.C., Bulu, S., Harris, J., Humphreys, D., Malverus, J. and Gray N.J. (2013) "Be Kind to Young People so They Feel at Home": A Qualitative Study of Adolescents' and Service Providers' Perceptions of Youth-Friendly Sexual and Reproductive Health Services in Vanuatu. BMC Health Services Research, 13, 455. https://doi.org/10.1186/1472-6963-13-455

[64] Han, C.-S. (2009) Chopsticks Don't Make It Culturally Competent: Addressing Larger Issues for HIV Prevention among Gay, Bisexual, and Queer Asian Pacific Islander Men. Health \& Social Work, 34, 273-281. https://doi.org/10.1093/hsw/34.4.273

[65] DiStefano, A.S., et al. (2012) Contextualization of HIV and HPV Risk and Prevention among Pacific Islander Young Adults in Southern California. Social Science \& Medicine, 75, 699-708. https://doi.org/10.1016/j.socscimed.2012.04.011

[66] Linh, N.N., Huong, N.T. and Thuy, H.T. (2015) Evolving Trade Policy and the Trans-Pacific Partnership Agreement: Does It Threaten Vietnam's Access to Medicine and Its Progress towards Scaling up HIV Prevention, Treatment and Care? Global Public Health, 10, S149-S160. https://doi.org/10.1080/17441692.2014.981829

[67] Wilson, P.A. and Yoshikawa, H. (2004) Experiences of and Responses to Social Discrimination among Asian and Pacific Islander Gay Men: Their Relationship to HIV Risk. AIDS Education and Prevention, 16, 68. https://doi.org/10.1521/aeap.16.1.68.27724

[68] Smith, G., Kippax, S., Aggleton, P. and Tyrer, P. (2003) HIV/AIDS School-Based Education in Selected Asia-Pacific Countries. Sex Education: Sexuality, Society and Learning, 3, 3-21. https://doi.org/10.1080/1468181032000052126 
[69] Reidpath, D. and Chan, K. (2005) HIV Discrimination: Integrating the Results from a Six-Country Situational Analysis in the Asia Pacific. AIDS Care, 17, 195-204.

https://doi.org/10.1080/09540120500120278

[70] Nemoto, T., Operario, D., Soma, T., Bao, D., Vajrabukka, A. and Crisostomo, V. (2003) HIV Risk and Prevention among Asian/Pacific Islander Men Who Have Sex with Men: Listen to Our Stories. AIDS Education and Prevention, 15, 7.

https://doi.org/10.1521/aeap.15.1.5.7.23616

[71] Han, C.-S., Operario, D. and Choi, K.-H. (2011) If I Was Infected with HIV, I Would Be Letting My Family Down: Family Influences on Risk and Protective Factors for Unsafe Sex among Gay Asian Pacific Islander Men. Health, Risk \& Society, 13, 373-388. https://doi.org/10.1080/13698575.2011.575932

[72] MacLaren, D., et al. (2013) Foreskin Cutting Beliefs and Practices and the Acceptability of Male Circumcision for HIV Prevention in Papua New Guinea. BMC Public Health, 13, 818. https://doi.org/10.1186/1471-2458-13-818

[73] Rupali, P., Condon, R., Roberts, S., Wilkinson, L., Voss, L. and Thomas, M.G. (2007) Prevention of Mother to Child Transmission of HIV Infection in Pacific Countries. Internal Medicine Journal, 37, 216-223. https://doi.org/10.1111/j.1445-5994.2007.01309.x

[74] King, R., et al. (2011) Satisfaction with Sex and Erection Hardness: Results of the AsiaPacific Sexual Health and Overall Wellness Survey. International Journal of Impotence Research, 23, 135-141. https://doi.org/10.1038/ijir.2011.17

[75] Phongsavan, P., et al. (2005) Sexual Health Behaviours among Pacific Island Youth in Vanuatu, Tonga and the Federated States of Micronesia. Health Promotion Journal of Australia: Official Journal of Australian Association of Health Promotion Professionals, 16, 144.

[76] Meldrum, R.M., Liamputtong, P. and Wollersheim, D. (2015) Sexual Health Knowledge and Needs Young Muslim Women in Melbourne, Australia. International Journal of Health Services, 46, 124-140.

[77] Zenner, D. and Russell, S. (2005) Sexually Transmitted Diseases and HIV/AIDS in Vanuatu: A Cause for Concern and Action. The New Zealand Medical Journal, 118, U1610.

[78] Tynan, A., et al. (2013) Sociocultural and Individual Determinants for Motivation of Sexual and Reproductive Health Workers in Papua New Guinea and Their Implications for Male Circumcision as an HIV Prevention Strategy. Human Resources for Health, 11, 7. https://doi.org/10.1186/1478-4491-11-7

[79] Kennedy, E.C., Bulu, S., Harris, J., Humphreys, D., Malverus, J. and Gray, N.J. (2014) "These Issues Aren't Talked about at Home": A Qualitative Study of the Sexual and Reproductive Health Information Preferences of Adolescents in Vanuatu. BMC Public Health, 14, 770. https://doi.org/10.1186/1471-2458-14-770

[80] Yoshikawa, H., Wilson, P.A., Hsueh, J., Rosman, E.A., Chin, J. and Kim, J.H. (2003) What Front-Line CBO Staff Can Tell Us about Culturally Anchored Theories of Behavior Change in HIV Prevention for Asian/Pacific Islanders. American Journal of Community Psychology, 32, 143-158. https://doi.org/10.1023/A:1025611327030

[81] Vallely, A., et al. (2012) Intravaginal Practices and Microbicide Acceptability in Papua New Guinea: Implications for HIV Prevention in a Moderate-Prevalence Setting. BMC Research Notes, 5, 613. https://doi.org/10.1186/1756-0500-5-613

[82] Javier, J.R., et al. (2010) Lessons Learned from a Community-Academic Partnership Addressing Adolescent Pregnancy Prevention in Filipino American Families. Progress in Community Health Partnerships. Research, Education, and Action, 4, 305-313. 


\section{Data Extraction Sheet 1: Quantitative Studies}




Sasaki and Kameoka, [39]

Year: 2009

8 Country: Hawaii

Type of Study: Case-control study

Choi et al. [40]

Year: 2013

9 Country: United States Type of study: Descriptive study

Salud et al. [41]

Year: 2014

10 Country: United States Type of study: Descriptive cross-sectional study

Lachowsky et al. [42]

Year: 2014

11 Country: New Zealand Type of study: Cross-sectionals study

Cruz et al. [43]

Year: 2013

12 Country: Columbia Type of study: Retrospective study

Han et al. [44]

13

Year: 2014

Country: Australia

Type of study: Cohort study

Takahashi et al. [45]

Year: 2006

14 Country: United States Type of study: Descriptive study

Kahle et al. [46]

Year:2005

Country: United States

Type of study: Cohort study

Hahm et al. [47]

Year: 2009

16 Country: United States Type of study: Prospective cohort study
Participants: Adolescents students

Number: 4953

Female: 2491

Male: 2462

Age: $\leq 12$ to $\geq 18$ years old

Participants: Adult MSM

Number: 1196

Male: 1196

Age: 18 - 83 years

Participants: Young women

Number: 299

Female: 299

Age: 18 - 24 years

Mean age: 20 years,

SD: 1.77

Participants: Younger MSM

Number: 3352

Male: 3352

Age: 16 - 29 years

Mean age: 23.2 , SD: 3.5

Participants: Infants and pregnant women

Number: 181

Infants: 89

Age: Preterm \& term

Female: 92

Age: 14 - 38; Mean: 23.6

Participants: Younger and older HIV + patients

Number: 7142

Male: 4278

Female: 2864

Age: $<30$ years to $\geq 60$ years

Participants: Women and youth

Number: 313

Female: 313

Age: 15 to 24 years

Mean age: 26 years

Participants: MSM, higher-risk heterosexuals and injection drug users young adults

Number: 435

Male: 435

Age: 18 - 30+ years

Participants: Young female adults

Number: 7576

Female: 7576

Age: 18 - 27 years
Data collection:

Questionnaires

Sampling methods: Purposive

sampling

Place: School-based

Data collection: Focus group discussion, in-depth interview Sampling methods: Snowball sampling

Place: Community-based

Data collection:

Questionnaires

Sampling method: Purposive sample

Place: Community-based

Data collection: Questionnaire Sampling method: Purposive sample

Place: Community-based

Data collection: Questionnaire Sampling methods: Simple

Random sampling

Place: Hospital-based

Data collection: Questionnaire, observation

Sampling methods: Purposive sampling

Place: Hospital-based

Data collection: Questionnaire Sampling methods: Convenience sample Place: Community-based

Data collection: Questionnaire Sampling method: Purposive sample

Place: Community-based

Data collection: Questionnaire Sampling method: Clustered sample

Place: Community-based
Determinants (risk behaviour)

- Age

- Ethnicity

Risk factors

- Lifetime sexual intercourse

- Had sex before age 15

Determinant

- Ethnicity

- Sex and Gender

Determinants

- Knowledge level

- Sex and Gender

Risk factors

- Number of sexual partners

- Sexually active

Determinants

(services)

- Gender

- Age

- Ethnicity

Determinants

- Income

- Age

Risk factors

- contracted STI

Determinants

- Age

Determinants

- Sex and gender

- Age

Determinants

- Perceptions

Risk factors

- Low level condom use

- Injection drug use

Determinants (services)

- Sex and Gender

- Ethnicity 
Wong et al. [48]

17

Year: 2004

Country: United States

Type of study: Descriptive study

Wong et al. [49]

Year: 2012

18 Country: United States Type of study: Cross-sectional study

Do et al. [50]

Year: 2006

19 Country: United States Type of study: Cross-sectional study

Muller and Sami, [51]

Year: 2012

20 Country: Fiji

Type of study: Retrospective descriptive study

Hahm et al. [52]

Year: 2008

21

Country: United States

Type of study: Prospective study

Kang et al. [53]

Year: 2005

22 Country: United States Type of study: Cross-sectional study

Hahm et al. [54]

23

Year: 2007

Country: United States

Type of study: Descriptive study
Participants: HIV + patients

Number: 114

Male: Not reported

Female: Not reported

Age: $18+$ years

Mean age: 38.7 years,

SD: 9.3

Participants: men sex men

Number: 445

Male: 445

Age: $\geq 18$ years

Mean: 30.7; SD: 10.3

Participants: Young MSM

Number: 908

Male: 908

Age: 15 - 25 years

Participants: HIV-TB patients Number: 393 HIV Male: Not reported Female: Not reported Age: Not reported

Participants: Adolescents to young adulthood

Number: 1195

Male: Not reported Female: Not reported

Age: 22 - 24 years

Mean age: 22 years old

Participants: HIV+ patients Number: 54

Male: 45

Age: 24 - 58 years;

Mean: 42 years

Female: 8

Age: 20 - 65 years;

Mean: 42 years

Transgender: 1

Age: 45 years

Participants: Young adults Number: 1183

Male: 578

Female: 605

Age: 18 - 27 years old
Data collection: Questionnaire Sampling method: Purposive sample Place: Health centre-based

Data collection: Screening test, questionnaire,

Sampling method: Purposive and convenience sample

Place: Community-based

Data collection: Questionnaire Sampling method: Simple random sample

Place: Community-based

Data collection: Questionnaire, lab test

Sampling method: Purposive sample

Place: Hospital-based

Data collection: Questionnaires Sampling method: Clustered sample Place: Community-based

Data collection: Semi-structured questionnaire

Sampling method: Convenience sampling

Place: Community-based

Data collection: Questionnaire Sampling method: Clustered sample Place: Community-based
Determinant

- Ethnicity

- Education

Determinants (services)

- Age

- Sex and Gender

- Perceptions

- Healthcare services

Determinants (services)

- Sex and Gender

- Ethnicity

- Education

- Healthcare services

Risk factors

- Transactional sex

- Unprotected sex

Risk factors

- Tuberculosis

Determinants (risk behaviour)

- Social support network

- Perceptions

Risk factors

- Engage sex before age of 15

- Contracted STDs

- Number of sexual partners

- Traded sex for material

Determinants

- Environment

- Social support network
Determinants

- Gender

- Ethnicity

Risk factors

- Traded sex for material

- Had sex before age 15

- Number of sexual partners 
Lowry et al. [55]

Year: 2011

24 Country: United States

Type of study:

Cross-sectional study

Foliaki et al. [56]

Year: 2014

25 Country: Fiji

Type of study:

Cross-sectional study

Huang et al. [57]

Year: 2008

26 Country: United States Type of study: Descriptive study

Saewyc et al. [58]

Year: 2006

27 Country: United States, British Columbia Type of study: Cohort study

Choi et al. [59]

Year: 2013

28 Country: United States Type of study: Descriptive study

Han et al. [60]

Year: 2015

29 Country: United States Type of study: Descriptive study

Nemoto et al. [61]

Year: 2011

30 Country: United States Type of study: Descriptive study
Participants: High school students Number: 56,773

Male: Not reported

Female: Not reported

Age: Not reported

Mean age range: 15.9 - 16.1 years

Participants: Women

Number: 1244

Female: 1244

Age: 25 - 64 years

Participants: Non MSM adults

Number: 604

Male: Not reported

Female: Not reported

Age: 18 - 45 years old

Participants: Bisexual, gay/lesbian, heterosexual adolescents

Number: 800,750

Male: Not reported

Female: Not reported

Age: $<12->19$ years

Participants: MSM

Number: 1196

Male: 1196

Age: 18 - 83 years

Participants: MSM

Number: 1196

Male: 1196

Age: 18 - 83 years

Participants: MSM, substance abusers, incarcerated persons

Number: 1349

Male: Not reported

Female: Not reported

Age: $18-84$ years

Mean age: 28 years, S.D: 8.6
Risk factors

- Substance abuse

- Inconsistent condom use

Determinants (risk

behaviours)

- Ethnicity

- Individual lifestyle (sexually active)

Data collection: Questionnaires, Lab test

Sampling method: Convenience sample

Risk factors

- Contracted STI

Place: Health centre-based

Data collection: Questionnaires Sampling method: Snowball sample Place: Community-based

Determinants

- Education (knowledge, perceptions)

Data collection: Questionnaires Sampling method: Clustered stratified random sampling

Place: School-based

Determinants (risk behaviour)

- Individual lifestyle

- Sex and Gender

- Age

Prevalence

- $14 \%$

Data collection: Questionnaire Sampling method: Snowball sample Place: Community-based

\section{Determinants (risk}

behaviour)

- Social support network

- Social environment (Sex peer norms)

Data collection: Questionnaire, Sampling method: Snowball sample Place: Community-based

\section{Determinants}

- Social support network

Risk factors

- Unprotected sex

Prevalence

- $6 \%$

Data collection: Questionnaire

Determinants

- Sex and Gender

- Individual lifestyle sample

Place: Community-based

- Inconsistent condom use

- Substance users

\section{Data Extraction Sheet 2: Qualitative Studies}

\begin{tabular}{|c|c|c|c|c|}
\hline No. & Study/Article & Participants & Methodology & Results \\
\hline 1 & $\begin{array}{l}\text { Zayeri et al. [62] } \\
\text { Year: } 2016 \\
\text { Country: Asian and North } \\
\text { Africa } \\
\text { Type of study: Retrospective } \\
\text { study }\end{array}$ & $\begin{array}{l}\text { Participants: HIV/AIDS } \\
\text { patients. } \\
\text { Number: } 6 \text { areas (East Asia, } \\
\text { South Asia, Central Asia, } \\
\text { Asia Pacific, Middle East, } \\
\text { South East Asia) }\end{array}$ & $\begin{array}{l}\text { Data collection: Framework } \\
\text { questionnaires } \\
\text { Sampling methods: Cluster sample } \\
\text { Place: Population-based }\end{array}$ & $\begin{array}{l}\text { Determinants } \\
\text { - Gender }\end{array}$ \\
\hline
\end{tabular}


Kennedy et al. [63]

Year: 2013

2 Country: Vanuatu Type of study: Descriptive qualitative Study

Han, [64]

Year: 2009

3

Country: United States

Type of study: Descriptive study

DiStefano et al. [65]

Year: 2012

4 Country: United States Type of study: Descriptive qualitative study

Linh et al. [66]

5 Year: 2015

Country: Vietnam

Type of study: Case study design

Wilson and Yoshikawa, [67]

6

Year:2004

Country: United States

Type of study: Descriptive study

Smith et al. [68]

Year: 2003

Country: Brunei, Cambodia,

7 China, Indonesia, Malaysia, Mongolia, Myanmar, PNG, Philippines, Thailand, Vietnam Type of study: Descriptive study Reidpath and Chan, [69]

Year: 2005

8 Country: China, India, Indonesia, Philippines, Thailand, Vietnam Type of study: Descriptive study

Nemoto et al. [70]

9 Year: 2003

Country: United States

Type of study: Descriptive study
Participants: adolescents, policy makers and service providers)

Number: 341

Male: 169

Female: 172

Age: 15 - 19 years

Participants: Gay, bisexual and queer Asian Pacific

Islander men

Number: 15

Male: 15

Age: 18 to $50+$ years

Participants: Young adults,

children, community leaders,

health providers

Number: 95

Female: Unknown

Male: Unknown

Age: 11 - 29 years

Participants: Government,

academia, hospitals and civil

society

Number: 20

Female: Unknown

Male: Unknown

Age: Unknown

Participants: Asian and

Pacific Islander gay men

Number: 23

Male: 23

Age: 23 - 46 years

Mean age: 32 years

Participants: Adult population with HIV

Number: 150

Male: Unknown

Female: Unknown

Age: Unknown

Participants: 6 countries Number: Unknown

Male: Unknown

Female: Unknown

Age: Unknown

Participants: Young adults MSM

Number: 38

Male: 38

Age: 18 - 50 [average

age-39.4 years]
Data collection tools: Focus group discussion, semi-structured interview Sampling methods: Purposive sample Place: Community-based

Data collection tools: Focus group discussion, in-depth interview Sampling methods: Convenience sampling

Place: Community-based

Data collection: Focus group

discussion, interviews

Sampling methods: Purposive

sampling

Place: Community-based

Data collection: In-depth interview Sampling methods: Snowball sampling

Determinants

- Ethnicity

\section{Determinants}

- Age

Determinants

- Gender

- Ethnicity

Determinants

- Age
Data collection: In-depth interview, observation

Sampling method: Purposive sampling

Place: Community-based

Data collection: Questionnaires, interview

Sampling method: Snowball sample

Place: Population-based

Data collection: Interview, focus group discussion

Sampling method: Convenience sample

Place: Population-based

Data collection: Focus group discussion

Sampling method: Convenience sample

Place: Community-based

\section{Determinants}

Determinants

- Gender (experiences \& responses discrimination)

Determinants (services)

- Ethnicity

- Sexual practices

- Education

- Culture (interpersonal interaction (practice)

Determinants (risk behaviour)

- Gender

- Psychological

- Social

- Cultural

Risk factors

- Psychosocial risk

- Behavioural risk 


\section{Continued}

Han et al. [71]

10

Year: 2011

Country: United States

Type of study: Descriptive study

MacLaren et al. [72]

Year: 2013

11 Country: Papua New Guinea Type of study: Multi-method qualitative study

Rupali et al. [73]

Year: 2007

12 Country: 22 Pacific island countries territories

Type of study: Descriptive study

King et al. [74]

Year: 2011

13

Country: 13 Asia Pacific countries Type of study: Descriptive study

Phongsavan et al. [75]

Year: 2005

14 Country: Vanuatu, Tonga, Federated States of Micronesia Type of study: Descriptive study

Meldrum et al. [76]

Year: 2015

15

Country: Australia

Type of study: Descriptive study

Zenner and Russell, [77]

Year: 2005

16

Country: Vanuatu

Type of study: Descriptive study
Participants: Young gay

men

Number: 25

Male: 25

Age: 18 to 39 years

[mean-28]

Participants: Unmarried youths, key stakeholders, community members

Number: 482

Male: 272

Female: 210

Age: $<25$ years

Participants: Health care providers

Number: Unknown

Male: Unknown

Female: Unknown

Age: Unknown

Participants: Men and women who had sexual intercourse at least once in the past 12 months with opposite sex

Number: 3957

Male: 2016

Female: 1941

Age: 25 - 74 years

Participants: Youths dropped out of school

Number: 1416

Male: 917

Female: 499

Age: 15 - 19 years

Participants: Young Muslim women

Number: 11

Female: 11

Age: 18 - 25 years

Participants: Government officials, NGO workers

Number: 14

Male: Unknown

Female: Unknown

Age: Unknown
Data collection: Semi-structured interview

Sampling method: Snowball sample

Place: Community-based

Data collection: In-depth interview, focus group discussion Sampling method: Purposive sampling Place: Community-based

Data collection: Questionnaires Sampling method: Purpose sample Place: Population-based

Data collection: Questionnaires Sampling method: Convenience sample

Place: Population-based

Data collection: Questionnaires Sampling method: Convenience sample

Place: Church-based

Data collection: Semi-structured questionnaire

Sampling method: Snowball sample Place: Community-based

Data collection: Semi-structured questionnaires

Sampling method: Purposive sampling

Place: Health centre-based
Determinants (family influence on HIV risk behaviours)

- Gender

- Social environment

- Ethnicity

Determinants (prevention services)

- Social support network

- Culture

Prevalence of known HIV infection

- $\quad$ PNG: $>150$ per 100,000 persons

- French Polynesia, Guam, New Caledonia: 100 per 100,000 persons

- Tuvalu and other 14 countries: $<50$ per 100,000 persons

Determinants

- Ethnicity

Determinants

- Sex

\section{Determinants (risk} behaviour)

- Gender

- Ethnicity

Risk factors for HIV

- Multiple sexual partners

- Substance abuse

- Unprotected sex

Determinants

- Gender

- Culture

Determinants of HIV/AIDS

- Gender

- Environment 
Tynan et al. [78]

17

Year: 2013

Country: Papua New Guinea

Type of study: Descriptive study

Kennedy et al. [79]

Year: 2014

18

Country: Vanuatu

Type of study: Descriptive study

Yoshikawa et al. [80]

19

Year: 2003

Country: United States

Type of study: Descriptive studies

Vallely et al. [81]

Year: 2012

20 Country: Papua New Guinea Type of Study: Cross-sectional study
Participants: Medical

officers, nursing officers,

health extension

officers, CHWs, and support

staff

Number: 29

Male: 17

Female: 12

Age:

Participants: Adolescent

substance users, jailed

Number: 341

Male: Unknown

Female: Unknown

Age: 15 - 19 years

Participants: Peer educators

Number: 35

Male: 13

Female: 22

Age: 18 - 56 years old

[Mean: 34 yrs.]

Participants: University

students

Number: 1380

Male: 861

Female: 519

Age: $10-25+$ years old

Mean age: 17, SD-4.77
Data collection: In-depth interview, focus group discussion Sampling method: Purposive sample Place: Health centre-based
Determinants of access to HIV prevention services

- Sociocultural factors

- Individual factors
Data collection: Questionnaires, focus group discussion

Sampling method: Purposive sample

Place: Community-based

Data collection: Focus group discussion

Sampling method: Purposive sample

Place: Community-based

\section{Determinants}

- Social support network
Data collection: Questionnaires Sampling methods: Systematic sample Place: School-based and community-based

\section{Determinants}

- Culture

- Work environment

\section{Data Extraction Sheet 3: Interventional Studies}

\begin{tabular}{|c|c|c|c|c|}
\hline No. & Study/Article & Participants & Intervention & Results \\
\hline 1 & $\begin{array}{c}\text { Javier et al. }[82] \\
\text { Year: } 2010 \\
\text { Country: United } \\
\text { States } \\
\text { Type of study: } \\
\text { Descriptive study }\end{array}$ & $\begin{array}{c}\text { Participants: Filipino } \\
\text { teens and parents } \\
\text { Sample: Convenience } \\
\text { sample } \\
\text { Number: } 60 \\
\text { Intervention group: } \\
35 \text { adolescents, } 25 \\
\text { parents } \\
\text { Age: } \\
\text { Adolescent mean age: } \\
16.8 \text { yrs. } \\
\text { Parent mean age: } 43.5 \\
\text { yrs. } \\
\text { Place: Community } \\
\text { based (San Jose, CA) }\end{array}$ & $\begin{array}{c}\text { Package: Parent-teen conference } \\
\text { Who ran: Filipino Youth Coalition (FYC), [FYC } \\
\text { staff members, pastor, community members, Filipino } \\
\text { paediatrician, medical student, Filipina paediatrics] } \\
\text { How long: } 6 \text { weeks }\end{array}$ & $\begin{array}{l}\text { Conference was well received- } \\
\text { Both parents and youth report } \\
\text { conference was helpful [mean score } \\
\text { of } 4.5 \text { and } 4.7 \text { respectively] }\end{array}$ \\
\hline
\end{tabular}


Submit or recommend next manuscript to SCIRP and we will provide best service for you:

Accepting pre-submission inquiries through Email, Facebook, LinkedIn, Twitter, etc. A wide selection of journals (inclusive of 9 subjects, more than 200 journals)

Providing 24-hour high-quality service

User-friendly online submission system

Fair and swift peer-review system

Efficient typesetting and proofreading procedure

Display of the result of downloads and visits, as well as the number of cited articles

Maximum dissemination of your research work

Submit your manuscript at: http://papersubmission.scirp.org/

Or contact wja@scirp.org 